\title{
THE MECHANISM OF RETENTION OF VANADIUM OXO-SPECIES AT THE "TITANIUM OXIDE I AQUEOUS SOLUTION" INTERFACE
}

\author{
E. TELLA ${ }^{1}$ \\ G.D. PANAGIOTOU ${ }^{1}$ \\ T. PETSI ${ }^{1}$ \\ K. BOURIKAS ${ }^{2, *}$ \\ C. KORDULIS ${ }^{1,3}$ \\ A. LYCOURGHIOTIS ${ }^{1}$
}

\author{
${ }^{1}$ Department of Chemistry, University of Patras \\ GR-265 00 Patras, Greece \\ ${ }^{2}$ School of Science and Technology \\ Hellenic Open University \\ Tsamadou 13-15, GR-26222, Patras, Greece \\ ${ }^{3}$ Institute of Chemical Engineering
}

and High-Temperature Chemical Processes (FORTH/ICE-HT),

P.O. Box 1414, GR-265 00 Patras, Greece
Received: $16 / 06 / 10$

Accepted: 10/09/10 *to whom all correspondence should be addressed: e-mail: bourikas@eap.gr

\begin{abstract}
The mechanism of retention of vanadium oxo-species at the "titanium oxide/aqueous solution" interface was investigated over a wide $\mathrm{pH}$ range $(4-9)$ and $\mathrm{V}(\mathrm{V})$ solution concentration $\left(10^{-5}-2 \times 10^{-2} \mathrm{M}\right)$ by combining equilibrium deposition experiments, potentiometric titrations, microelectrophoresis and "proton-ion" titration curves. It was inferred that the adsorbed V(V) oxo-species are retained inside the compact layer of the interface through hydrogen/coordinative bonds forming very probably innersphere complexes with the titania surface groups.
\end{abstract}

KEYWORDS: Titania, vanadates, interface, adsorption, innersphere surface complex, equilibrium deposition filtration, aqueous solution, hydrogen bonds, pzc, iep.

\section{INTRODUCTION}

The presence of vanadium compounds in wastewater is a major water pollution problem. In fact, these compounds have harmful effects on the circulatory system and disturb the metabolism (Namasivayam and Sangeetha, 2006). In the case of plants, the latter causes chlorosis and limit growth (Kabata-Pendias and Pendias, 1993). Moreover, numerous reports have warned of the carcinogenic and other toxic effects of vanadium resulting from extensive industrial exposure (Abbasi, 1987). Vanadium is emitted into the environment from vanadium refineries, iron and steel industries and chemical industries (mainly phosphate industries) (Garcia-Sanchez et al., 2004). Several methods can be used to remove vanadium from aqueous solutions. Adsorption is a relatively inexpensive, non-hazardous, rapid and versatile technique which allows recovery of vanadium from the solid adsorbent. Various adsorbents have been used so far including high surface area carbon cloth (Abbas and Conway, 2002), iron oxyhydroxide (Blackmore et al., 1996), chitosan (Guzman et al., 2002; Jansson-Charrier et al., 1996), $\mathrm{ZnCl}_{2}$ activated carbon (Namasivayam, Sangeetha, 2006), amorphous ferric oxyhydroxide (Shieh and Duedall, 1988), modified silica (Garcia-Sanchez et al., 2004) as well as iron and titania based commercial adsorbents (Naeem et al., 2007).

The latter work indicated that titania is a promising adsorbent for removing vanadium species from aqueous media. Moreover, impressive progress has been pointed out in the last decade towards the preparation of anatase with very high specific surface area. Thus, the additional increase of the specific capacity of this adsorbent is anticipated. In spite of the great importance of the adsorption of the vanadium (V) oxo-species at the "anatase / aqueous solution" interface, the retention mechanism remains practically unknown, though electrostatic or chemical retention has been reported (Naeem et al., 2007; Bourikas et al., 1997). A modern picture has been recently developed for the structure of the aforementioned interface (Panagiotou et al., 2008). This indicates that two types of oxo- 
groups with different charges are developed on the titanium oxide surface: the terminal oxo-groups $\left(\mathrm{TiO}^{-0.35}\right)$ and the bridging ones $\left(\mathrm{Ti}_{2} \mathrm{O}^{-0.57}\right)$. Almost all terminal oxygens are non-protonated at $\mathrm{pH}$ values higher than $\mathrm{pzc}$, but even at low $\mathrm{pH}$ values they are predominant. In contrast, the greater portion of the bridging oxygens is protonated even at relatively high $\mathrm{pH}$ values. Moreover, according to this structure, the interface is divided by three charged planes into three sub - regions (see Figure 1). The surface plane is located at the oxygen atoms of the (hydr)oxo-groups. Plane 1 (Plane 2) is located at the oxygen atoms of the first (second) layer of structured water molecules surrounding the titania surface. The distance of the plane 1 from the surface is equal to the distance of the plane 2 from the plane $1(1.7 \AA)$. The first two regions constitute the compact layer of the interface. The third sub - region, up to bulk solution, is the diffuse layer. The shear plane is situated to the solution side with respect to the plane 2 . It divides the interface into two parts: the stagnant one, which "accompanies" the titania aggregates when they are moved under the influence of an electric field, and the external part which is separated from the moving aggregates. The diffuse layer is divided, thus, into the stagnant - diffuse layer and the mobile - diffuse layer. The counter ions and the coions are distributed among the various sub-regions. Those located inside the compact layer form ion-pairs with the opposite charged surface (hydr)oxo groups.

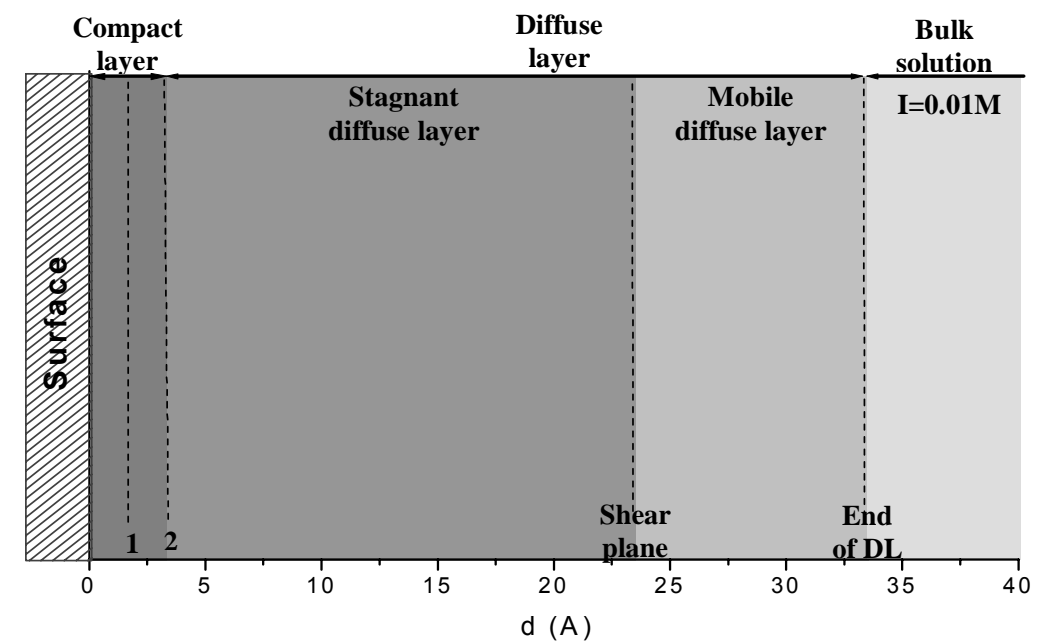

Figure 1. Structure of the "titanium oxide / aqueous solution" interface

(I: ionic strength, d: distance from the surface)

The establishment of the mechanism of retention of vanadium oxo-species at the "titania / aqueous solution" interface involves the elucidation of the nature of the retention forces (electrostatic, hydrogen bonds, coordinative bonds), the plane (layer) of the interface where these species are located, the local structure of these species and the determination of the surface speciation in a wide range of $\mathrm{pH}$ and $\mathrm{V}(\mathrm{V})$ solution concentration. The elucidation of the first two points is the goal of the present preliminary work. This is attempted by combining equilibrium deposition experiments, potentiometric titrations, microelectrophoresis and proton-ion titration curves.

\section{EXPERIMENTAL}

\section{Substances}

$\mathrm{NaNO}_{3}$ dissolved in triply distilled $\mathrm{CO}_{2}$-free water and $\mathrm{NaVO}_{3}$ were used for the preparation, respectively, of the indifferent electrolyte and adsorbate solutions, necessary for the deposition, microelecrophoresis, proton-ion, $\mathrm{pH}$-equilibrium and potentiometric titration experiments.

Industrial titania (Degussa P25) containing $80 \% \mathrm{w} / \mathrm{w}$ anatase and $20 \% \mathrm{w} / \mathrm{w}$ rutile was used for preparing the suspensions. Its surface composition is $\sim 90 \%$ anatase and $\sim 10 \%$ rutile (Spanos et al., 1995, Contescu et al., 1996) and its BET SSA equal to $50 \mathrm{~m}^{2} \mathrm{~g}^{-1}$.

\section{Equilibrium deposition experiments}

A thermostated double walled Pyrex vessel equipped with a magnetic stirrer and a perspex lid with holes for electrodes and nitrogen gas has been used. The control (change) of the $\mathrm{pH}$ during the deposition (titration) experiments was carried out by an automatic microburette (Radiometer Copenhagen ABU901 Autoburette) equipped with a combination $\mathrm{pH}$ electrode. The experiments 
were performed at $25 \pm 0.1^{\circ} \mathrm{C}$ and ionic strength $0.1 \mathrm{M}$ adjusted with sodium nitrate. Nitrogen gas was bubbled through the titania suspensions during the experiments to prevent the dilution of the atmospheric $\mathrm{CO}_{2}$, which would bring about a change in the $\mathrm{pH}$.

Adsorption edges were derived for three different initial $\mathrm{V}(\mathrm{V})$ concentrations $\left(3 \times 10^{-3} \mathrm{M}, 6 \times 10^{-3} \mathrm{M}\right.$ and $2 \times 10^{-2} \mathrm{M}$ ) over the $\mathrm{pH}$ range $4-10$, using a solid concentration of $20 \mathrm{~g} \mathrm{~L}^{-1}$. Details concerning the experimental procedure have been reported elsewhere (Bourikas et al., 2001). In all adsorption experiments the equilibrium $\mathrm{V}(\mathrm{V})$ concentration in the adsorbate solutions was determined spectrophotometrically at $392 \mathrm{~nm}$ (Snell, 1978).

The change of $\mathrm{pH}$ upon deposition was measured in each equilibrium deposition experiment. The experiments were performed at initial $\mathrm{pH}$ values 5 and 9 and four different values of the initial $\mathrm{V}(\mathrm{V})$ concentration.

\section{Proton-ion titrations at constant $\mathrm{pH}$}

Proton-ion titrations were performed at six $\mathrm{pH}$ values $(4,5,6,7,8,9)$ under conditions favoring complete deposition of the $\mathrm{V}(\mathrm{V})$ oxo-species at the interface (low initial $\mathrm{V}(\mathrm{V})$ concentrations). Details for the experimental procedure have been reported elsewhere (Bourikas et al., 2001).

\section{Electrochemical techniques}

Potentiometric titrations were used for determining the point of zero charge of the suspensions, both in the absence and presence and of the $\mathrm{V}(\mathrm{V})$ oxo-species. They were performed, under $\mathrm{N}_{2}$ atmosphere, at three different values of the ionic strength $(0.1,0.01$ and $0.001 \mathrm{~N})$ and constant temperature $\left(25.0 \pm 0.1^{\circ} \mathrm{C}\right)$. Details about the experimental procedure and the derivation of "surface charge density vs pH" curves have been reported elsewhere (Bourikas et al., 2003; Bourikas et al., $2005)$. The potentiometric titrations in the presence of the $V(V)$ oxo-species were performed at a $\mathrm{V}(\mathrm{V})$ concentration equal to $5 \times 10^{-5} \mathrm{M}$ where the whole amount of the $\mathrm{V}(\mathrm{V})$ oxo-species is practically deposited at the interface. It should be mentioned that after each addition of the titrant the $\mathrm{pH}$ stabilized quickly $((\Delta \mathrm{pH} / \mathrm{min})<0.01)$ and the solubility of the titania was negligible over the entire $\mathrm{pH}$ studied, even in the presence of the $\mathrm{V}(\mathrm{V})$ oxo-species.

The $\zeta$ potential of the suspensions was determined in the $\mathrm{pH}$ range $2-8$, both in the absence and presence of the $\mathrm{V}(\mathrm{V})$ oxo-species, at four initial $\mathrm{V}(\mathrm{V})$ concentrations $\left(6 \times 10^{-6} \mathrm{M}, 10^{-5} \mathrm{M}, 5 \times 10^{-5} \mathrm{M}\right.$ and $10^{-4} \mathrm{M}$ ), using a Zetasizer 5000 (Malvern Instruments Ltd) microelectrophoresis apparatus. Details for the experimental procedure have been reported elsewhere (Bourikas et al., 2003).

\section{Simulations}

The $V(V)$ speciation in the solution was carried out under conditions similar to those of the deposition experiments using Visual MINTEQ, a computer code for calculating chemical equilibria in aqueous media (Gustafsson, 2005).

\section{RESULTS AND DISCUSSION}

\section{The $V(V)$ oxo-species in the adsorbate solution}

Two monomer $\left(\mathrm{HVO}_{4}{ }^{2-}, \mathrm{H}_{2} \mathrm{VO}_{4}{ }^{-}\right)$, one dimmer $\left(\mathrm{H}_{2} \mathrm{~V}_{2} \mathrm{O}_{7}{ }^{2-}\right)$, one quadramer $\left(\mathrm{V}_{4} \mathrm{O}_{12}{ }^{4-}\right)$, one quintamer $\left(\mathrm{V}_{5} \mathrm{O}_{15}{ }^{5-}\right)$ and one decamer $\left(\mathrm{NaHV}_{10} \mathrm{O}_{28}{ }^{4-}\right) \mathrm{V}(\mathrm{V})$ oxo -species are present in the vanadate solutions. The distribution of vanadium in the various $\mathrm{V}(\mathrm{V})$ oxo-species depends on both the solution $\mathrm{pH}$ and the $\mathrm{V}(\mathrm{V})$ total concentration (see Figure 2).

Vanadium is present almost exclusively in the form of the $\mathrm{H}_{2} \mathrm{VO}_{4}{ }^{-}$at too low vanadium total concentration $\left(3 \times 10^{-5} \mathrm{M}\right)$ and in the whole $\mathrm{pH}$ range studied (4-9). Vanadium is mainly present in the form of the monomer $\mathrm{H}_{2} \mathrm{VO}_{4}{ }^{-}$species at relatively low $\mathrm{V}(\mathrm{V})$ total concentration $\left(3 \times 10^{-4} \mathrm{M}\right)$ whereas a smaller amount of vanadium is present in the form of the $\mathrm{H}_{2} \mathrm{~V}_{2} \mathrm{O}_{7}{ }^{2-}$ and $\mathrm{V}_{4} \mathrm{O}_{12}{ }^{4-}$ species. A significant portion of the $\mathrm{V}(\mathrm{V})$ is present as $\mathrm{NaHV}_{10} \mathrm{O}_{28}{ }^{4-}$ species at $\mathrm{pH}$ lower than 5.5. This portion increases as $\mathrm{pH}$ decreases.

The speciation is more complicated at an intermediate $\mathrm{V}(\mathrm{V})$ total concentration $\left(3 \times 10^{-3} \mathrm{M}\right)$. Vanadium is mainly present as the monomer oxo-species at $\mathrm{pH}$ greater than 8.5 , whereas it is mainly distributed among the monomers $\left(\mathrm{HVO}_{4}{ }^{2-}, \mathrm{H}_{2} \mathrm{VO}_{4}{ }^{-}\right)$, the dimmer, $\mathrm{H}_{2} \mathrm{~V}_{2} \mathrm{O}_{7}{ }^{2-}$ and the quadramer $\mathrm{V}_{4} \mathrm{O}_{12}{ }^{4-}$ in the $\mathrm{pH}$ range 8.5-5.5. Vanadium is mainly present in the form of the decamer $\mathrm{NaHV}_{10} \mathrm{O}_{28}{ }^{4-}$ at $\mathrm{pH}$ lower than 5 . 

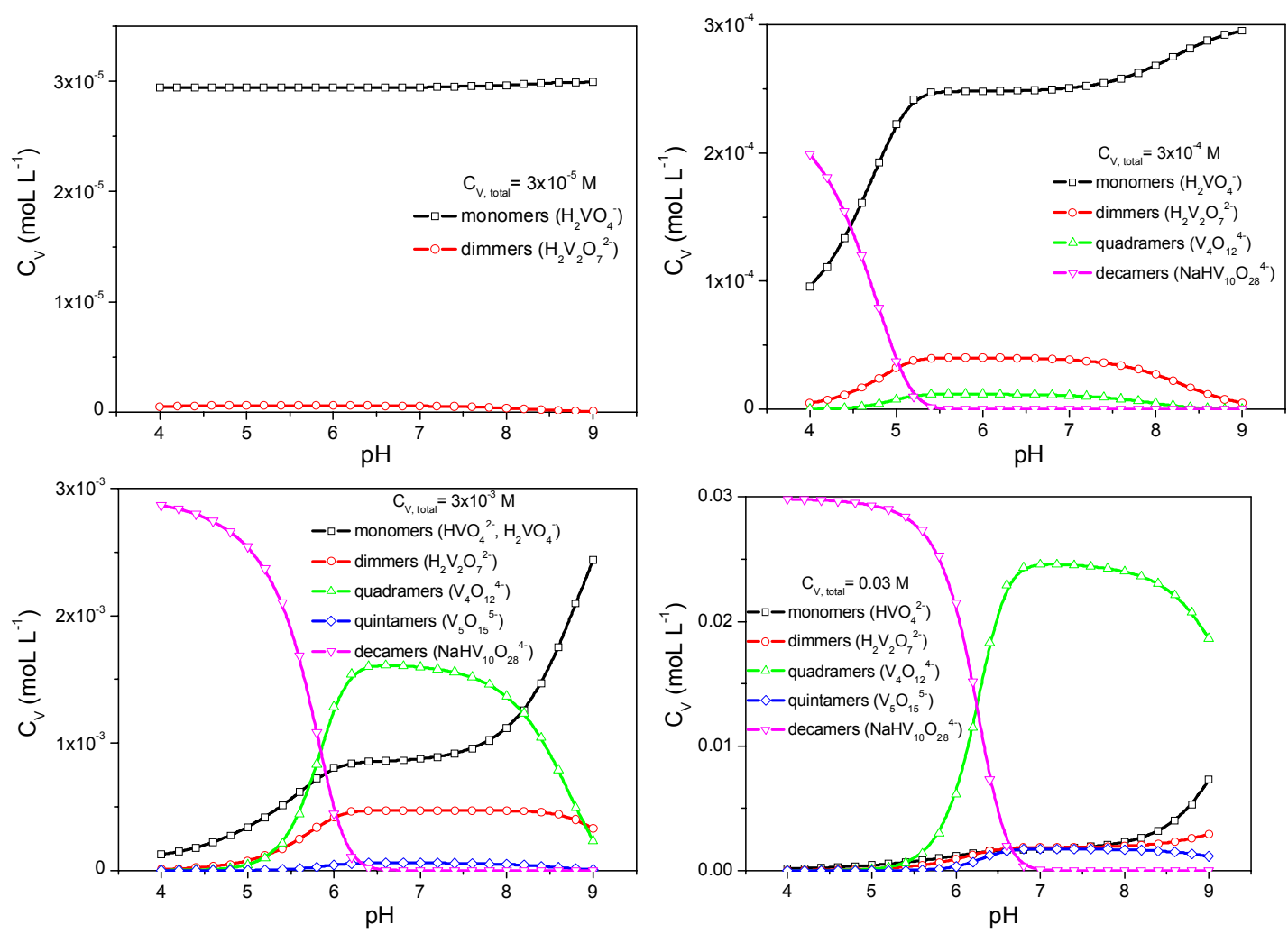

Figure 2. Distribution of $\mathrm{V}(\mathrm{V})$ (expressed as vanadium concentration, $\mathrm{C}_{\mathrm{V}}$ ) among the various $\mathrm{V}(\mathrm{V})$ oxo-species over the $\mathrm{pH}$ range $4-9$, for four different $\mathrm{V}(\mathrm{V})$ total concentrations $\left(\mathrm{C}_{\mathrm{V}}\right.$, total $)$ of an aqueous solution with $\mathrm{I}=0.1 \mathrm{M} \mathrm{NaNO}_{3}$

Finally, vanadium is mainly distributed between the $\mathrm{V}_{4} \mathrm{O}_{12}{ }^{4-}$ and $\mathrm{NaHV}_{10} \mathrm{O}_{28}{ }^{4-}$ species at relatively high $\mathrm{V}(\mathrm{V})$ total concentration $\left(3 \times 10^{-2} \mathrm{M}\right)$. The former prevails at $\mathrm{pH}$ values higher than 7 whereas the latter at $\mathrm{pH}$ values lower than 5.5 .

Overall, decrease of $\mathrm{pH}$ and increase of the total vanadium concentration favor the vanadium distribution in the polymer species. This is the normal behavior encountered in the oxo-species of the transition metals.

\section{Retention of $\mathrm{V}(\mathrm{V})$ oxo-species at the "titanium oxide I aqueous solution" interface}

Figure 3 shows the variation of the $\mathrm{V}(\mathrm{V})$ surface concentration with the $\mathrm{pH}$ of the adsorbate solution for three initial $V(V)$ solution concentrations.

It is observed that the surface $\mathrm{V}(\mathrm{V})$ concentration is maximized at $\mathrm{pH}=4$ and initial solution concentration equal to $2 \times 10^{-2} \mathrm{M}$. Comparison of this value with the maximum values obtained for other transition metal ionic species on the same adsorbent (see Table 1) confirms that titanium oxide is an excellent adsorbent of the $\mathrm{V}(\mathrm{V})$ oxo-species. This finding in conjunction with the impressive progresses of the last decade with respect to the preparation of titanias with very high specific surface areas renders this oxide a quite promising material for removing these species from aqueous solutions.

\section{Investigating the retention mode of $\mathrm{V}(\mathrm{V})$ oxo-species at the "titanium oxide $I$ aqueous solution" interface by deposition experiments}

Figure 3 shows that the surface $\mathrm{V}(\mathrm{V})$ concentration increases as $\mathrm{pH}$ decreases. Taking into account the negative charge of the retained $V(V)$ oxo-species and the fact that the surface charge of the support becomes positive below pzc (6.4) and then increases as $\mathrm{pH}$ decreases, we might propose that the deposition takes place through simple electrostatic accumulation of the $\mathrm{V}(\mathrm{V})$ oxo-species in the diffuse part of the interface (see Figure 1). But this retention mode cannot explain the observation that considerable deposition takes place even at $\mathrm{pH}$ higher than or equal to $\mathrm{pzc}$ of the support, where its surface was initially neutral or negatively charged. This observation strongly 
suggests some kind of specific interactions of the $V(V)$ oxo-species with the surface (hydr)oxogroups and presumably formation of inner sphere surface complexes (Bourikas et al., 2006a; Panagiotou et al., 2006; Bourikas et al., 2006b).

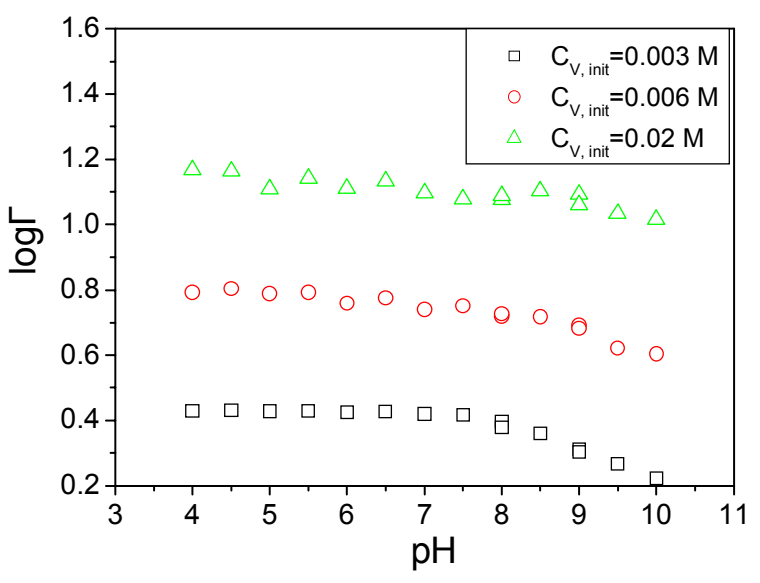

Figure 3. Variation of the $\mathrm{V}(\mathrm{V})$ surface concentration $\left(\Gamma: \mu \mathrm{mol} \mathrm{m} \mathrm{m}^{-2}\right)$ with the $\mathrm{pH}$ of the adsorbate solution (adsorption edge) obtained

in the $\mathrm{pH}$ range $4-10$, for three initial $\mathrm{V}(\mathrm{V})$ concentrations $\left(\mathrm{C}_{\vee \text {,init }}\right)$ in the solution

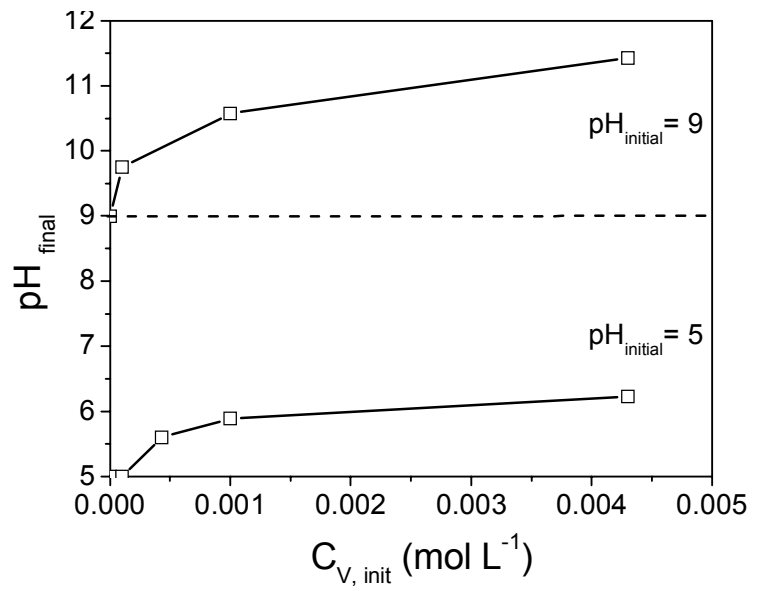

Figure 4. Increase of $\mathrm{pH}$ upon the deposition of the $\mathrm{V}(\mathrm{V})$ oxo-species at the "titanium oxide / adsorbate solution" interface for various initial $\mathrm{V}(\mathrm{V})$ solution concentrations $\left(\mathrm{C}_{\mathrm{V}, \text { init }}\right)$ and two values of initial $\mathrm{pH}$

Table 1. Maximum values of the surface concentration of various transition metal ionic species adsorbed on the titania surface

\begin{tabular}{lcccc}
\hline \multicolumn{1}{c}{ Species } & $\begin{array}{c}\text { Initial } \\
\text { concentration }\end{array}$ & $\begin{array}{c}\text { Optimum } \\
\mathrm{pH}\end{array}$ & $\begin{array}{c}\text { Surface } \\
\text { density } \\
\mu \mathrm{mol} \mathrm{m}^{-2}\end{array}$ & Reference \\
\hline $\mathrm{V}(\mathrm{V})$ oxo-species & $2 \times 10^{-2} \mathrm{M}$ & 4.0 & 15 & This work \\
\hline $\mathrm{Cr}(\mathrm{VI})$ oxo-species & $2.5 \times 10^{-2} \mathrm{M}$ & 4.5 & 4 & Petsi (2006) \\
\hline $\mathrm{Mo}(\mathrm{VI})$ oxo-species & $1.5 \times 10^{-2} \mathrm{M}$ & 4.0 & 6 & Panagiotou et al. $(2010)$ \\
\hline $\mathrm{W}(\mathrm{VI})$ oxo-species & $3 \times 10^{-2} \mathrm{M}$ & 4.0 & 11 & Panagiotou et al. (2009) \\
\hline $\mathrm{Co}(\mathrm{II})$ aqua complex & $2 \times 10^{-2} \mathrm{M}$ & 7.5 & 7 & Petsi et al. (2009) \\
\hline $\mathrm{Ni}(\mathrm{II})$ aqua complex & $2 \times 10^{-2} \mathrm{M}$ & 7.5 & 8 & Stavropoulos $(2010)$ \\
\hline
\end{tabular}

The mode of interfacial deposition may be further investigated by studying the change of $\mathrm{pH}$ upon the deposition of the $\mathrm{V}(\mathrm{V})$-oxo species. This change is illustrated in Figure 4.

It is clear that the deposition of the $\mathrm{V}(\mathrm{V})$ oxo-species causes a considerable increase of $\mathrm{pH}$. The magnitude of the effect increases with the initial $V(V)$ solution concentration and thus, with the surface $\mathrm{V}(\mathrm{V})$ concentration. The observed increase of $\mathrm{pH}$ upon deposition corroborates the development of specific interactions and presumably the formation of inner sphere complexes, at least for some of the deposited $\mathrm{V}(\mathrm{V})$ oxo-species. In fact, following this retention mode some of the $\mathrm{V}(\mathrm{V})$ oxo-species are located inside the compact layer of the interface (see Figure 1). Negative charge is, thus, accumulated in this region of the interface. The adsorption of hydrogen ions into one or more of the charged planes of the compact layer (surface plane, plane 1 or plane 2) is therefore expected to compensate the increase in the negative charge.

Investigating the retention mode of $\mathrm{V}(\mathrm{V})$ oxo-species at the "titanium oxide $I$ aqueous solution" interface by potentiometric titrations and microelectrophoresis.

The "surface charge density vs pH" curves are given in Figure 5 . These are recorded at three values of ionic strength in the presence of the $\mathrm{V}(\mathrm{V})$ oxo-species in the adsorbate solution. It is well known that the pzc is identified by the common intersection point of these curves. A considerable increase in the pzc value from 6.4 into 8.4 is observed. This increase strongly suggests the development of specific interactions and presumably formation of inner sphere complexes (Bourikas et al., 2006a; Panagiotou et al., 2006; Bourikas et al., 2006b). In fact, as already mentioned, the deposition of the 
$\mathrm{V}(\mathrm{V})$ oxo-species inside the compact layer is accompanied by $\mathrm{H}^{+}$adsorption. This takes place at all $\mathrm{pH}$ values including $\mathrm{pH}=\mathrm{pzc}$, where the surface was neutral before deposition. Thus, in the presence of the deposited $\mathrm{V}(\mathrm{V})$ oxo-species, we need more hydroxyls in the solution in order to deprotonate surface groups and restore a zero proton charge at the surface.

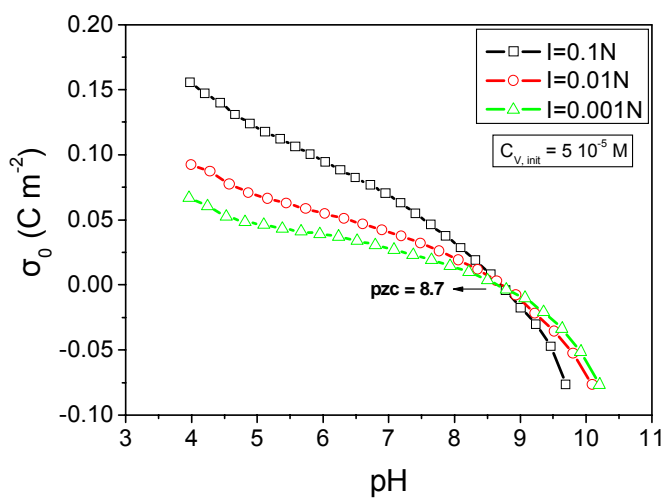

Figure 5. "Surface charge density $\left(\sigma_{0}\right)$ vs $\mathrm{pH}$ " curves in the presence of an initial $\mathrm{V}(\mathrm{V})$ concentration in the adsorbate solution $\left(\mathrm{C}_{\mathrm{V} \text {,init }}\right)$ for 3 different values of the ionic strength

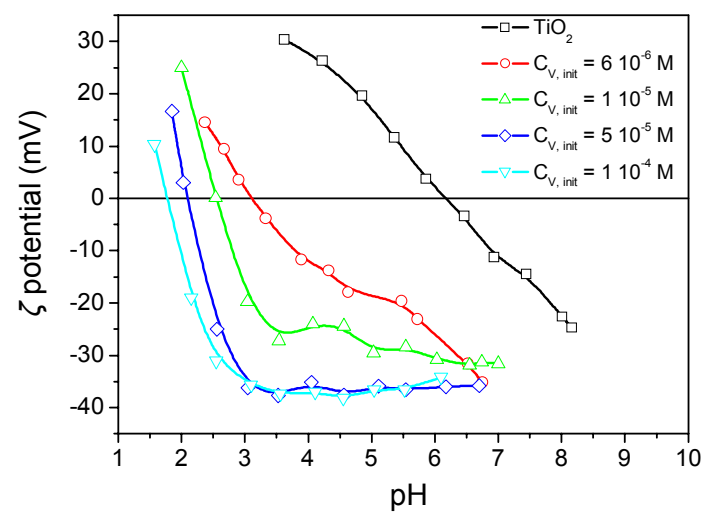

Figure 6. " $\zeta$ potential vs $\mathrm{pH}$ " curves obtained both in the absence and presence of the $\mathrm{V}(\mathrm{V})$ oxo-species in the adsorbate suspension, at various initial $\mathrm{V}(\mathrm{V})$ solution concentrations $\left(\mathrm{C}_{\mathrm{V} \text {,init }}\right)$ and ionic strength equal to $0.01 \mathrm{M}$

It is well known that the isoelectric point (iep) is the $\mathrm{pH}$ value where the $\zeta$ potential takes a zero value. The $\zeta$ potential is the potential at the shear plane of the interface (see Figure 1). Figure 6 shows that the $\zeta$ potential decreases and the iep shifts to lower values due to the presence of the $\mathrm{V}(\mathrm{V})$ oxo-species in the adsorbate solution. The effects become more and more pronounced increasing the initial $\mathrm{V}(\mathrm{V})$ concentration in the solution and thus, the amount of the $\mathrm{V}(\mathrm{V})$ adsorbed. These effects indicate accumulation of the negatively charged $V(V)$ oxo-species at the compact and/or stagnant-diffuse part of the interface (Bourikas et al., 2006a; Panagiotou et al., 2006; Bourikas et al., 2006b). In fact, in such a case the values of the $\zeta$ potential should decrease over the whole $\mathrm{pH}$ range studied. Moreover, the iep should be shifted to a lower value because a surface protonation is required to restore the electrokinetic charge, and thus, the $\zeta$ potential at zero value. The high intensity of the effects suggests accumulation of the aforementioned species at the compact rather than at the stagnant-diffuse part of the interface. This is related to the development of specific interactions and presumably to the formation of inner sphere complexes located inside the compact layer. Overall, the microelectrophoresis results corroborate the potentiometric titration results, the deposition data and the change of $\mathrm{pH}$ suggesting specific interactions of the $\mathrm{V}(\mathrm{V})$ species and presumably formation of inner sphere complexes.

\section{Investigation of the mode of interfacial deposition and the structure of the deposited species by studying "proton-ion" curves}

The deposition of the $\mathrm{V}(\mathrm{V})$ oxo-species and the hydrogen ion adsorption may be combined quantitatively in the context of a methodology based on the so called "proton-ion" titration curves (Bourikas et al., 2006a; Panagiotou et al., 2006; Bourikas et al., 2006b). These are linear plots of the "amount of the $\mathrm{H}^{+}$ions adsorbed versus the amount of the deposited $\mathrm{V}(\mathrm{V})$ ". Each of the aforementioned plots is determined at a fixed $\mathrm{pH}$ and under conditions favoring complete deposition of the $\mathrm{V}(\mathrm{V})$ oxo-species at the interface (low $\mathrm{V}(\mathrm{V})$ initial concentration). The ratio "amount of the $\mathrm{H}^{+}$ ions adsorbed versus the amount of the deposited $\mathrm{V}(\mathrm{V})$ ") can be determined from the slope of each curve. These plots were derived at various $\mathrm{pH}$ values in the $\mathrm{pH}$ range 9-4 (Figure 7). The experimentally determined amounts of the adsorbed protons were properly corrected to take into account changes in $\mathrm{pH}$ caused due to dilution of the solution disturbing the equilibria between the $\mathrm{V}(\mathrm{V})$ oxo- species. A similar procedure has been reported elsewhere (Petsi, 2006; Panagiotou et al., 2010; Panagiotou et al., 2009). 


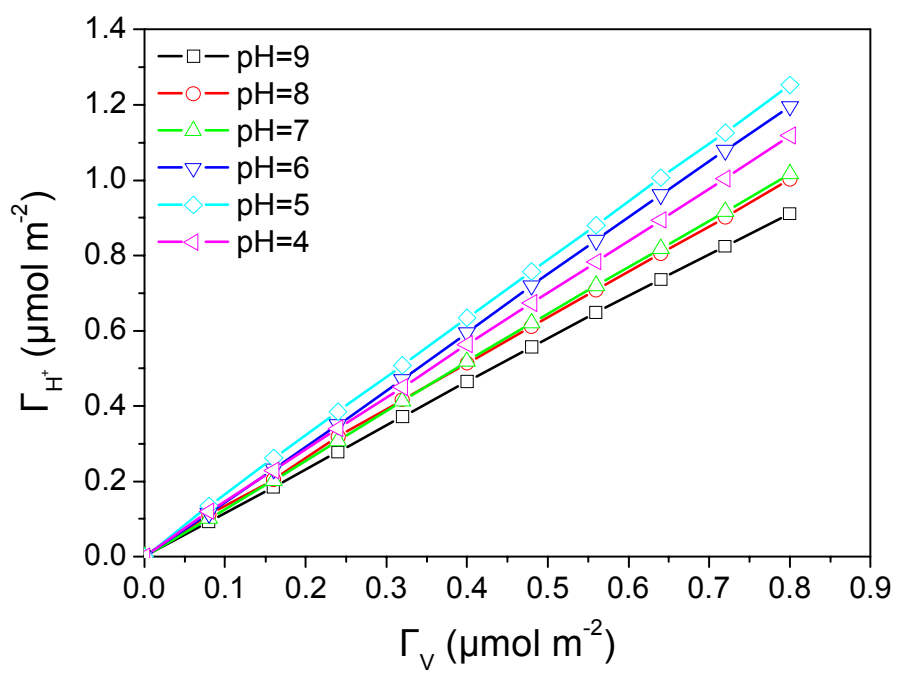

Figure 7. "Amount of the $\mathrm{H}^{+}$ions adsorbed $\left(\Gamma_{\mathrm{H}^{+}}\right)$vs the amount of the deposited $\mathrm{V}(\mathrm{V})\left(\Gamma_{\mathrm{V}}\right)$ ". Each curve corresponds to a given $\mathrm{pH}$ value.

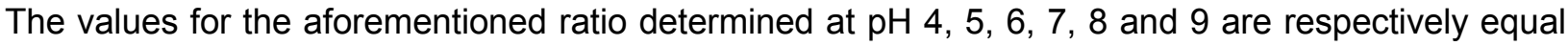
to $1.4,1.6,1.5,1.3,1.3$ and 1.2. These were derived for initial solution $\mathrm{V}(\mathrm{V})$ concentration in the range $\left(8 \times 10^{-5}-8 \times 10^{-4} \mathrm{M}\right)$. The monomers $\mathrm{H}_{2} \mathrm{VO}_{4}{ }^{-}$are actually present in the solution in this range. Therefore, the mode of interfacial deposition investigated in this sub-section is related only to these species. The values obtained for the ratio are relatively large indicating location of the deposited $\mathrm{H}_{2} \mathrm{VO}_{4}{ }^{-}$species very close to the surface and thus, deposition through hydrogen bonds or formation of inner sphere complexes (Bourikas et al., 2006a; Panagiotou et al., 2006; Bourikas et al., 2006b). The increase of this ratio as $\mathrm{pH}$ decreases presumably indicates increasing contribution of the inner sphere complexes at expense of the hydrogen bonding species. Alternatively, this may reflect increasing formation of a di-substituted at expense of a mono-substituted inner sphere complex.

\section{CONCLUSIONS}

Titanium oxide is an excellent adsorbent of the $\mathrm{V}(\mathrm{V})$ oxo-species. The amount of the vanadium adsorbed on $\mathrm{TiO}_{2}$ surface increases with decreasing $\mathrm{pH}$ and it is maximized at $\mathrm{pH}=4$ and initial solution concentration equal to $2 \times 10^{-2} \mathrm{M}$. The joint use of $\mathrm{V}(\mathrm{V})$ equilibrium adsorption experiments, change of $\mathrm{pH}$ upon $\mathrm{V}(\mathrm{V})$ adsorption, potentiometric titrations and microelectrophoresis in the presence of $\mathrm{V}(\mathrm{V})$ oxo-species in the solution, as well as "proton-ion" titration curves suggested that the adsorbed $\mathrm{V}(\mathrm{V})$ oxo-species are retained inside the compact layer of the " $\mathrm{TiO}_{2}$ / aqueous solution" interface through hydrogen/coordinative bonds.

\section{REFERENCES}

Abbas A. and Conway B.E. (2002) Investigation of Removal of $\mathrm{Cr}(\mathrm{VI}), \mathrm{Mo}(\mathrm{VI}), \mathrm{W}(\mathrm{VI}), \mathrm{V}(\mathrm{IV})$, and $\mathrm{V}(\mathrm{V})$ Oxy-ions from Industrial Waste-Waters by Adsorption and Electrosorption at High-Area Carbon Cloth, J. Colloid Interface Sci., 251, 248-255.

Abbasi S.A. (1987) Trace analysis of vanadium in the environment as its ternary complex with $\mathrm{N}-\mathrm{p}$ methoxyphenyl I-2- furacrylodroxamic acid and 3-(0-carboxyphenyl) - 1- phenyltriazine - $\mathrm{N}$ - oxide, Anal. Lett., 20, 1347-1361.

Blackmore D.P.T., Ellis J. and Riley P.J. (1996) Treatment of a vanadium-containing effluent by adsorption/coprecipitation with iron oxyhydroxide, Water. Res., 30, 2512-2516.

Bourikas K., Georgiadou I., Kordulis Ch. and Lycourghiotis A. (1997) Mechanism of Deposition of Vanadium-Oxo Species on the "Anatase/Electrolytic Solution" Interface, J. Phys. Chem. B, 101, 8499-8506.

Bourikas K., Hiemstra T. and Van Riemsdijk W.H. (2001) Adsorption of Molybdate Monomers and Polymers on Titania with a Multisite Approach, J. Phys. Chem. B, 105, 2393-2403.

Bourikas K., Vakros J., Kordulis Ch. and Lycourghiotis A. (2003) Potentiometric Mass Titrations: Experimental and Theoretical Establishment of a New Technique for Determining the Point of Zero Charge (PZC) of Metal (Hydr)Oxides, J. Phys. Chem. B, 107, 9441-9451. 
Bourikas K., Kordulis Ch. and Lycourghiotis A. (2005) Differential Potentiometric Titration: Development of a Methodology for Determining the Point of Zero Charge (PZC) of Metal (Hydr)Oxides by One Titration Curve, Environ. Sci. Technol., 39, 4100-4108.

Bourikas K., Kordulis Ch. and Lycourghiotis A. (2006a) The role of the liquid - solid interface in the preparation of supported catalysts, Catal. Rev., 48, 363-444.

Bourikas K., Panagiotou G.D., Petsi Th., Kordulis Ch. and Lycourghiotis A. (2006b) Investigation of the mode of interfacial deposition and the local structure of transition metal ionic species formed upon impregnation at the "catalytic support/electrolytic solution" interface, Stud. Surf. Sci. Catal., 162, 251-258.

Contescu C., Popa V. and Schwarz J.A. (1996) Heterogeneity of Hydroxyl and Deuteroxyl Groups on the Surface of $\mathrm{TiO}_{2}$ Polymorphs, J. Colloid Interface Sci., 180, 149-161.

Garcia-Sanchez R., Bettmer J. and Ebdon L. (2004) Development of a new method for the separation of vanadium species and chloride interference removal using modified silica capillaries-DIN-ICP-MS, Microchemical Journal, 76, 161-171.

Guzman J., Saucedo I., Navarro R., Revilla J. and Guibal E. (2002) Vanadium Interactions with Chitosan: Influence of Polymer Protonation and Metal Speciation, Langmuir, 18, 1567-1573.

Gustafsson J.P. (2005) Visual MINTEQ ver. 2.40, Department of Land and Water Resources Engineering, Royal Institute of Technology, Stockholm.

Jansson-Charrier M., Guibal E., Roussy J., Delanghe B. and LeCloirec P. (1996) Vanadium (IV) sorption by chitosan: kinetics and equilibrium, Water Res., 30, 465-475.

Kabata-Pendias A. and Pendias H. (1993) Biochemistry of trace elements, PWN, Warsaw, Poland.

Naeem A., Westerhoff P. and Mustafa S. (2007) Vanadium removal by metal (hydr)oxide adsorbents, Water Res., 41, 1596-1602.

Namasivayam C. and Sangeetha D. (2006) Removal and recovery of vanadium(V) by adsorption onto $\mathrm{ZnCl}_{2}$ activated carbon: Kinetics and isotherms, Adsorption, 12, 103-117.

Panagiotou G.D., Petsi Th., Stavropoulos J., Bourikas K., Garoufalis Ch.S., Kordulis Ch. and Lycourghiotis A. (2006) Towards the local structure of the $\mathrm{Co}(\mathrm{II}), \mathrm{Ni}(\mathrm{II}), \mathrm{Cr}(\mathrm{VI})$ and $\mathrm{W}(\mathrm{VI})$ ionic species formed upon impregnation on titania, Stud. Surf. Sci. Catal., 162, 809-816.

Panagiotou G.D., Petsi Th., Bourikas K., Garoufalis Ch.S., Tsevis A., Spanos N., Kordulis Ch. and Lycourghiotis A. (2008) Mapping the surface (hydr)oxo-groups of titanium oxide and its interface with an aqueous solution: the state of the art and a new approach, Adv. Colloid Interface Sci., 142, 20-42.

Panagiotou G.D., Petsi Th., Bourikas K., Kordulis Ch. and Lycourghiotis A. (2009) The Interfacial Chemistry of the Impregnation Step Involved in the Preparation of Tungsten (VI) Supported Titania Catalysts, J. Catal., 262, 266-279.

Panagiotou G.D., Petsi Th., Bourikas K., Kalampounias A.G., Boghosian S., Kordulis Ch. and Lycourghiotis A. (2010) Interfacial Impregnation Chemistry in the Synthesis of Molybdenum Catalysts supported on Titania, J. Phys. Chem. C, 114, 11868-11879.

Petsi Th. (2006) Ph.D. thesis, University of Patras, Chemistry Department, Patras, Greece.

Petsi Th., Garoufalis Ch.S., Panagiotou G.D., Kordulis Ch., Stathi P., Deligiannakis Y., Lycourghiotis A. and Bourikas K. (2009) Interfacial Impregnation Chemistry in the Synthesis of Cobalt Catalysts Supported on Titania, Chem. Eur. J., 15, 13090-13104.

Shieh C.S. and Duedall I.W. (1988) Role of amorphous ferric oxyhydroxide in removal of anthropogenic vanadium from seawater, Marine Chemistry, 25, 121-139.

Snell F.D. (1978) Photometric and Fluorometric Methods of Analysis of Metals, Wiley, New York, Vol. 2, p. 1235.

Spanos N., Georgiadou I. and Lycourghiotis A. (1995) Investigation of rutile, anatase, and industrial titania/water solution interfaces using potentiometric titration and microelectrophoresis, J. Colloid Interface Sci., 172, 374-382.

Stavropoulos J. (2010) Ph.D. thesis, University of Patras, Chemistry Department, Patras, Greece. 